( Д.Ш. Авзалетдинова", Т.В. Моругова' ${ }^{1}$, Л.Ф. Шарипова', О.В. Кочетова²

1Башкирский государственный медицинский университет, Уфа

2Уфимский федеральный исследовательский центр Российской академии наук, Уфа

Многофакторная природа сахарного диабета 2 типа (СД2) была неоднократно продемонстрирована множеством исследований. Первые работы, посвященные молекулярно-генетическим механизмам СД2, выполнены на основе изучения неравновесности по сцеплению (linkage disequilibrium - LD), несколько позже стали проводить исследования «генов-кандидатов» СД2. В Российской Федерации в настоящее время выполнено большое количество работ по поиску генетических маркеров СД2.

Нами был проведен анализ данных литературы, включающей исследования по принципу случай-контроль в популяциях России. В приведенных работах было выявлено 33 гена и 65 полиморфных маркеров. Анализ ассоциаций СД2 в популяциях РФ проводился по генам: ABCC8, ADIPOQ, ADIPOR1, ADIPOR2, C2CD4A/C2CD4A, CDKAL1, CDKN2A/2B, CCL11, CCL20, CCL5, CYBA, FABP2, FTO, GCLC, GPX2, GSTP1, GSTT1, HHEX/IDE, IGF2BP2, IRS1, KCNJ11, KCNQ1, LPL, LRP5, MC4R, PPARG, SLC2A2, SLC30A8, SLC30A8, TCF7L2, TMEM18, WFS1, ZFAND6. Большинство исследований являются репликативными, т.е. повторяющими предшествующие работы зарубежных авторов, и выполнены в русской, татарской и якутской популяциях. При этом не все локусы генетической предрасположенности продемонстрировали ассоциацию с Сд2 в популяциях России.

КЛЮЧЕВЫЕ СЛОВА: сахарный диабет 2 типа; полногеномный поиск GWAS; инсулинорезистентность; бета-клетки; полиморфизм генов

\title{
ASSOCIATION OF POLYMORPHIC LOCI OF SUSCEPTIBILITY TO DIABETES MELLITUS TYPE 2 IN VARIOUS ETHNIC GROUPS OF THE RUSSIAN FEDERATION
}

\author{
(c) Diana S. Avzaletdinova ${ }^{1 *}$, Tatyana V. Morugova', Liaisan F. Sharipova', Olga V. Kochetova ${ }^{2}$
}

${ }^{1}$ Bashkir State Medical University, Ufa, Russia

${ }^{2}$ Ufa Federal Research Centre of the Russian Academy of Sciences, Ufa, Russia

The multifactorial nature of type 2 diabetes mellitus (T2D) was confirmed by numerous researches. The first investigations devoted to molecular-genetic mechanisms of T2D were carried out on the basis of linkage disequilibrium (LD) studying and later the candidate genes of T2D have begun investigated.

We have analyzed the literature data including the case-control studies in populations of Russia. There were revealed 33 genes and 65 polymorphic markers in the analyzed works. The analysis of association of T2D in the ethnic groups of Russian Federation was carried out on following genes: ABCC8, ADIPOQ, ADIPOR1, ADIPOR2, C2CD4A/C2CD4A, CDKAL1, CDKN2A/2B, CCL11, CCL20, CCL5, CYBA, FABP2, FTO, GCLC, GPX2, GSTP1, GSTT1, HHEX/IDE, IGF2BP2, IRS1, KCNJ11, KCNQ1, LPL, LRP5, MC4R, PPARG, SLC2A2, SLC30A8, SLC30A8, TCF7L2, TMEM18, WFS1, ZFAND6. The major of studies are replicative, i.e. repeating previous investigations of foreign authors, and were performed on Russian, Tatar and Yakut populations. At the same time not all the loci of genetic susceptibility have demonstrated the association with T2D in the population of Russia.

In this work the systematic review of studies of molecular-genetic markers of T2D in the ethnic groups of Russian Federation was made for the first time.

KEYWORDS: type 2 diabetes mellitus; genome wide association study GWAS; insulin resistance; beta-cells; genetic polymorphisms

Сахарный диабет 2 типа (СД2) является наиболее распространенным заболеванием в структуре эндокринной патологии и одной из острейших медико-социальных проблем, поскольку приводит к ранней инвалидизации и повышению показателей смертности среди населения по причине развития микро- и макрососудистых осложнений.
Согласно прогнозам Международной федерации диабета (IDF — International Diabetes Federation), число больных СД во всем мире в 2019 г. составило 463 млн человек, а к 2045 г. увеличится до 700 млн.

В основе этиопатогенеза СД2 лежит взаимодействие наследственных и средовых факторов, поэтому исследования ассоциации полиморфных генетических маркеров 
с СД2 являются одним из актуальных направлений современной медицины.

В настоящее время установлено, что к развитию СД2 предрасполагают аллельные варианты порядка 100 генов [1]. Большая часть работ по исследованию роли различных генов-кандидатов в развитии СД2 выполнена за рубежом, преимущественно в популяциях европейцев, а также в китайской, японской популяциях [2-4].

Вариабельность генетических маркеров СД2 в разных популяционных группах подтверждает особую роль этнической составляющей риска развития заболевания.

Целью данного исследования является обзор литературы генетических исследований, проведенных в России, для лучшего понимания генетической эпидемиологии СД2 в популяциях, проживающих на территории РФ.

\section{МЕТОДЫ ПОИСКА И ОТБОРА ЛИТЕРАТУРЫ}

Систематический поиск проводился с использованием баз данных Google Scholar и Web of Science и ключевых слов «полиморфизм генов, ассоциированных с СД2 в России», а также по отдельным генам и однонуклеотидным полиморфизмам, ассоциированным с СД2. Исследования по метаболическому синдрому, ожирению, гестационному диабету, так же, как работы, акцентированные на осложнениях СД2, MODY-диабете, сахарном диабете у детей, исключались из анализа. При анализе исследований, в которых отсутствовали данные показателя соотношения шансов (OR - odds ratio), производили расчет этого показателя с использованием онлайн-программы (https://www.medcalc.org/calc/odds_ratio.php).

\section{РЕЗУЛЬТАТЫ}

Всего было проанализировано 26 ген-кандидатных исследований по принципу случай-контроль в популяциях России (русские, татары, якуты). В приведенных исследованиях было выявлено 33 гена и 65 полиморфных маркеров, ассоциированных с СД2 (табл. 1). Гены, по которым проводился анализ ассоциаций с СД2 в популяциях России: $A B C C 8, A D I P O Q, A D I P O R 1$, ADIPOR2, C2CD4A/C2CD4A, CDKAL1, CDKN2A/2B, CCL11, CCL20, CCL5, CYBA, FABP2, FTO, GCLC, GPX2, GSTP1, GSTT1, HHEX/IDE, IGF2BP2, IRS1, KCNJ11, KCNQ1, LPL, LRP5, MC4R, PPARG, SLC2A2, SLC30A8, SLC30A8, TCF7L2, TMEM18, WFS1, ZFAND6.

Ниже представлены гены, по которым выявлена ассоциация в популяции русских, татар и якутов, ссылка на литературный источник приведена в табл. 1: ABCС8 (rs1799859), CDKN2A/2B (rs10811661), WFS1 (rs752854, rs10010131, rs734312) у русских и у якутов, ADIPOQ (rs2241766) у якутов; ADIPOQ (rs17366743), ADIPOR2 (rs11061971, rs16928751), C2CD4A (rs7172432), CDKAL1 (rs7756992, rs9465871, rs10946398), ZFAND6 (rs11634397), CYBA (rs4673), GCLC (rs17883901), GPX2 (rs4602346), GSTP1 (rs1695), GSTT1 (делеция), LRP5 (rs3736228), MC4R (rs571312), PPARG (rs1801282), SLC30A8 (rs13266634), FTO (rs8050136, rs11642841) у русских; CCL11 (rs16969415), CCL20 (rs6749704), CCL5 (rs2107538), FABP2 (rs1799883) у татар; IGF2BP2 (rs1470579, rs11927381, rs11705701), IRS1 (rs2943634, rs2943641), KCNJ11 (rs5219), KCNQ1 (rs163184) у русских; $L P L$ (rs285, rs320) у якутов и татар, TCF7L2 (rs7903146, rs12255372) у русских и татар.

Среди полиморфных локусов генов, показавших ассоциацию, 13 являются аминокислотными заменами, 16 - интронными полиморфизмами, 4 - промоторными маркерами, 8 - межгенными полиморфными маркерами и 1 - делецией 54 кб.

Из выявленных локусов подтверждение в разных популяциях было получено для генов $A B C C 8$ (rs1799859), ADIPOR2 (rs11061971), CDKN2A/2B (rs10811661), KCNJ11 (rs5219), LPL (rs320), SLC30A8 (rs13266634), TCF7L2 (rs7903146) (см. табл. 1).

В отношении популяций, В которых проводился анализ, известно, что русские и татары, по ранее полученным данным, относятся к европеоидам, популяция якутов является смешанной, с преобладанием восточно-евразийского компонента [5-6].

Общепринятой классификации генетических маркеров предрасположенности к СД2 нет, вместе с тем многие авторы выделяют из них две большие группы - это гены, ответственные за функцию инсулинпродуцирующих бета-клеток, и гены, продукты которых имеют отношение к патогенезу инсулинорезистентности.

Гены, вовлеченные в функционирование бета-клеток

Показано, что из полиморфных маркеров с выявленной ассоциацией гены $A B C C 8, I G F 2 B P 2, I R S 1, C D K A L 1$, KCNJ11, KCNQ1, SLC30A8, C2CD4A, WFS1, TCF7L2, GCK относят к системе, связанной с бета-клеточной функцией.

Продукты генов KCNJ11 и ABCC8 кодируют субъединицы АТФ-зависимого калиевого канала панкреатических бета-клеток (Kir6.2 и SUR1). Мутации генов KCNJ11 и ABCC8 способны уменьшать или нивелировать функцию метаболической чувствительности АТФ-зависимых калиевых каналов бета-клеток, что приводит к постоянной деполяризации клеточной мембраны и персистированию инсулиновой секреции даже в условиях очень низкой плазменной концентрации глюкозы.

По данным отечественных авторов, локус rs5129 (Glu23Lys) гена KCNJ11 ассоциирован с повышенным риском СД2 (в работе Вахромеевой К.А. (2015) данная ассоциация не показана) [7-9].

Полиморфный локус Glu23Lys гена KCNJ11 ассоциирован со сниженной секрецией инсулина и развитием СД2, что подтверждено данными метаанализов и полногеномных поисков [2, 10-11].

В европеоидных и монголоидных популяциях была показана ассоциация полиморфного локуса гена рецептора сульфонилмочевины ABCC8 (rs1799859) с развитием СД2 [12-13]. Известно, что полиморфный локус rs1799859 гена $A B C C 8$ обусловливает повышение уровня инсулина в крови в ответ на увеличение глюкозы. Продукт этого гена контролирует электрическую активность мембраны бета-клеток, за счет деполяризации мембраны и повышения концентрации ионов $\mathrm{Ca}^{2+}$ происходит более активный экзоцитоз инсулина.

Ген ингибитора циклинзависимых киназ $C D K N 2 A / B$ участвует в регуляции клеточного цикла, пролиферации бета-клеток островков Лангерганса и дифференциации клеток. Полиморфизм rs10811661 гена CDKN2A/B, белковый продукт которого влияет на секрецию инсулина, ассоциирован с СД2 по данным полногеномных поисков, 
Таблица 1. Анализ генов, исследованных при сахарном диабете 2 типа в популяциях Российской Федерации

\begin{tabular}{|c|c|c|c|c|c|c|c|c|c|}
\hline Ген & $\begin{array}{l}\text { Хромо- } \\
\text { сома }\end{array}$ & RefSNP & Замена & Эффект & $\begin{array}{c}\text { СД2/ } \\
\text { контроль }\end{array}$ & $\begin{array}{c}\text { OR } \\
(95 \% \mathrm{Cl})\end{array}$ & $\mathbf{P}$ & $\begin{array}{c}\text { Популя- } \\
\text { ция }\end{array}$ & Ссылка \\
\hline$A B C C 8$ & 11 & rs1799859 & c. $3819 \mathrm{G}>\mathrm{A}$ & Arg $>$ Arg & $376 / 210$ & $\begin{array}{c}1,51 \\
(1,07-2,15)\end{array}$ & 0,005 & Русские & [8] \\
\hline$A B C C 8$ & 11 & rs1799859 & c. $3819 \mathrm{G}>\mathrm{A}$ & Arg $>$ Arg & - & 1,339 & 0,03 & Якуты & [13] \\
\hline$A B C C 8$ & 11 & rs1799859 & c. $3819 G>A$ & $\operatorname{Arg}>\operatorname{Arg}$ & $213 / 213$ & 1,34 & 0,04 & Якуты & {$[55]$} \\
\hline$A B C C 8$ & 11 & rs1799857 & c. $1686 C>T$ & His $>$ His & $204 / 348$ & 1,10 & 0,609 & Якуты & [13] \\
\hline$A B C C 8$ & 11 & rs1799857 & c. $1686 C>T$ & His $>$ His & $204 / 348$ & 1,10 & 0,56 & Якуты & [13] \\
\hline$A B C C 8$ & 11 & rs1799858 & g.53521G $>C / C>T$ & Lys > Lys & $204 / 348$ & 1,04 & 0,51 & Якуты & {$[13]$} \\
\hline$A B C C 8$ & 11 & rs1799854 & c. $2117-3 C>T$ & Интрон & $204 / 348$ & 1,024 & 0,80 & Якуты & {$[13]$} \\
\hline$A B C C 8$ & 11 & rs1048099 & c. $207 \mathrm{~T}>\mathrm{C} / \mathrm{A}$ & Pro > Pro & $204 / 348$ & 1,05 & 0,91 & Якуты & {$[13]$} \\
\hline$A B C C 8$ & 11 & rs757110 & c. $4108 \mathrm{G}>\mathrm{T} / \mathrm{A}$ & $\begin{array}{l}\text { Ala }>\text { Thr/ } \\
\text { Ala }>\text { Ser }\end{array}$ & $204 / 348$ & 1,20 & 0,16 & Якуты & {$[13]$} \\
\hline$A B C C 8$ & 11 & rs2237982 & c. $1630+3555 G>A$ & Интрон & $204 / 348$ & 1,12 & 0,30 & Якуты & {$[13]$} \\
\hline ADIPOQ & 3 & rs 2241766 & c. $45 \mathrm{~T}>\mathrm{G}$ & Gly > Gly & $129 / 117$ & - & - & Русские & {$[29]$} \\
\hline ADIPOQ & 3 & rs2241766 & $\mathrm{c.} .45 \mathrm{~T}>\mathrm{G}$ & Gly > Gly & $500 / 500$ & $\begin{array}{c}1,07 \\
(0,74-1,54)\end{array}$ & 0,9188 & Русские & {$[30]$} \\
\hline ADIPOQ & 3 & rs2241766 & c. $45 \mathrm{~T}>\mathrm{G}$ & Gly $>$ Gly & & $\begin{array}{c}2,61 \\
(1,05-5,38)\end{array}$ & 0,047 & Якуты & {$[56]$} \\
\hline ADIPOQ & 3 & rs2241766 & $c .45 \mathrm{~T}>\mathrm{G}$ & Gly > Gly & $204 / 348$ & 1,11 & 0,66 & Якуты & [13] \\
\hline ADIPOQ & 3 & rs1501299 & c. $214+62 G>C$ & Intron & $500 / 500$ & $\begin{array}{c}1,02 \\
(0,80-1,31) \\
\end{array}$ & 0,7106 & Русские & [30] \\
\hline ADIPOQ & 3 & rs1501299 & c. $214+62 G>C$ & Intron & $204 / 348$ & 1,08 & 0,86 & Якуты & {$[13]$} \\
\hline ADIPOQ & 3 & rs17366743 & c.331T $>C$ & Tyr $>$ His & $399 / 365$ & $\begin{array}{c}2,56 \\
(1,62-4,05)\end{array}$ & 0,0002 & Татары & {$[28]$} \\
\hline ADIPOQ & 3 & rs17366743 & c. $331 \mathrm{~T}>\mathrm{C}$ & Tyr $>$ His & $204 / 348$ & 1,19 & 0,18 & Якуты & [13] \\
\hline ADIPOQ & 3 & rs266729 & g.4012C>T & Промотор & $204 / 348$ & 1,153 & 0,28 & Якуты & [13] \\
\hline ADIPOR1 & 1 & rs2275738 & c. $-94-12 A>G$ & Интрон & $129 / 117$ & - & - & Русские & [29] \\
\hline ADIPOR1 & 1 & rs2275738 & c. $-94-12 A>G$ & Интрон & $500 / 500$ & $\begin{array}{c}1,31 \\
(1,00-1,72)\end{array}$ & 0,1467 & Русские & [30] \\
\hline ADIPOR1 & 1 & rs2275737 & c. $-94-8 \mathrm{~T}>\mathrm{G}$ & Интрон & $500 / 500$ & $\begin{array}{c}1,09 \\
(0,84-1,41)\end{array}$ & 0,7698 & Русские & {$[30]$} \\
\hline ADIPOR2 & 12 & rs11061971 & c. $171+48 A>G$ & Интрон & $129 / 117$ & $\begin{array}{c}4,45 \\
(1,75-11,28)\end{array}$ & 0,0015 & Русские & [29] \\
\hline ADIPOR2 & 12 & rs11061971 & c. $171+48 A>G$ & Интрон & $500 / 500$ & $\begin{array}{c}1,63 \\
(1,13-2,35) \\
\end{array}$ & 0,011 & Русские & [30] \\
\hline ADIPOR2 & 12 & rs11061971 & c. $171+48 A>G$ & Интрон & $96 / 96$ & - & - & Русские & [34] \\
\hline
\end{tabular}


Продолжение таблицы 1

\begin{tabular}{|c|c|c|c|c|c|c|c|c|c|}
\hline Ген & $\begin{array}{l}\text { Хромо- } \\
\text { сома }\end{array}$ & RefSNP & Замена & Эффект & $\begin{array}{c}\text { СД2/ } \\
\text { контроль }\end{array}$ & $\begin{array}{c}\text { OR } \\
(95 \% \mathrm{Cl})\end{array}$ & $\mathbf{P}$ & $\begin{array}{c}\text { Популя- } \\
\text { ция }\end{array}$ & Ссылка \\
\hline ADIPOR2 & 12 & rs16928751 & g.1781033G $>A$ & $\mathrm{Gln}>\mathrm{Gln}$ & $96 / 96$ & - & - & Русские & {$[34]$} \\
\hline ADIPOR2 & 12 & rs16928751 & g.1781033G $>A$ & $\mathrm{Gln}>\mathrm{Gln}$ & $129 / 117$ & $\begin{array}{c}0,52 \\
(0,29-0,91)\end{array}$ & 0,018 & Русские & [29] \\
\hline ADIPOR2 & 12 & rs16928751 & g.1781033G $>A$ & $\mathrm{Gln}>\mathrm{Gln}$ & $500 / 500$ & $\begin{array}{c}1,16 \\
(0,55-2,46)\end{array}$ & 0,1476 & Русские & [30] \\
\hline$C 2 C D 4 A$ & 15 & rs7172432 & g.62396389A >G & Межгенный & $96 / 96$ & $\begin{array}{c}1,60 \\
(1,01-2,52)\end{array}$ & 0,04 & Русские & [19] \\
\hline CDKAL1 & 6 & rs7756992 & c. $371+30101 A>G$ & Интрон & $440 / 264$ & $\begin{array}{c}2,08 \\
(1,27-3,42)\end{array}$ & 0,008 & Русские & {$[57]$} \\
\hline CDKAL1 & 6 & rs9465871 & g.187568T>C & Интрон & $440 / 264$ & $\begin{array}{c}1,45 \\
(1,16-1,81)\end{array}$ & 0,001 & Русские & {$[57]$} \\
\hline$C D K A L 1$ & 6 & rs7754840 & c. $371+11642 \mathrm{G}>\mathrm{A}$ & Интрон & $440 / 264$ & $\begin{array}{c}0,87 \\
(0,44-1,72)\end{array}$ & 0,45 & Русские & [57] \\
\hline CDKAL1 & 6 & rs7754840 & $c .371+11642 \mathrm{G}>\mathrm{A}$ & Интрон & $204 / 348$ & 1,0 & 0,29 & Якуты & [13] \\
\hline CDKAL1 & 6 & rs10946398 & C. $371+11426 \mathrm{~A}>\mathrm{C}$ & Интрон & $440 / 264$ & $\begin{array}{c}1,67 \\
(0,87-3,21)\end{array}$ & 0,042 & Русские & {$[57]$} \\
\hline$C D K N 2 A / 2 B$ & 9 & rs10811661 & g.22134094T >A & Межгенный & $440 / 264$ & $\begin{array}{c}2,11 \\
(1,34-3,32)\end{array}$ & 0,0001 & Русские & [7] \\
\hline$C D K N 2 A / 2 B$ & 9 & rs10811661 & g.22134094T $>A$ & Межгенный & $204 / 348$ & 1,38 & 0,04 & Якуты & {$[13]$} \\
\hline$C D K N 2 A / 2 B$ & 9 & rs10811661 & g.22134094T $>A$ & Межгенный & $96 / 96$ & - & - & Русские & [19] \\
\hline CCL11 & 17 & rs16969415 & g. $4716 \mathrm{C}>\mathrm{T}$ & Промотор & $440 / 500$ & $\begin{array}{c}1,50 \\
(1,02-2,22)\end{array}$ & 0,04 & Татары & {$[42]$} \\
\hline CCL2O & 2 & rs6749704 & g.228677842T $>C$ & Промотор & $440 / 500$ & $\begin{array}{c}1,46 \\
(1,20-1,78)\end{array}$ & 0,0001 & Татары & {$[42]$} \\
\hline CCL5 & 17 & rs2107538 & $\mathrm{g} .4598 \mathrm{G}>\mathrm{A}$ & Промотор & $440 / 500$ & $\begin{array}{c}1,78 \\
(1,46-2,18) \\
\end{array}$ & 0,0001 & Татары & {$[42]$} \\
\hline CYBA & 16 & rs7195830 & g.12746T>C & 3' конец & $1024 / 1034$ & $\begin{array}{c}1,01 \\
(0,71-1,45) \\
\end{array}$ & 0,98 & Русские & {$[50]$} \\
\hline$C Y B A$ & 16 & rs8854 & g.3593G $>A$ & 3/ конец & $1024 / 1034$ & $\begin{array}{c}4,45 \\
(0,76-25,96) \\
\end{array}$ & 0,077 & Русские & {$[50]$} \\
\hline$C Y B A$ & 16 & rs9932581 & g.4105G >A & 3/ конец & $1024 / 1034$ & $\begin{array}{c}0,89 \\
(0,69-1,14)\end{array}$ & 0,51 & Русские & {$[50]$} \\
\hline$C Y B A$ & 16 & rs4673 & g.9222T>C & Tyr $>$ Asn & $1024 / 1034$ & $\begin{array}{c}1,51 \\
(1,09-2,09) \\
\end{array}$ & 0,014 & Русские & {$[50]$} \\
\hline$F A B P 2$ & 4 & rs1799883 & c. $163 \mathrm{~A}>\mathrm{T}$ & Thr $>$ Ala & $130 / 503$ & $\begin{array}{c}1,66 \\
(0,82-3,36)\end{array}$ & 0,05 & Татары & {$[45]$} \\
\hline FTO & 16 & rs8050136 & c. $46-27777 C>A$ & Интрон & $440 / 264$ & - & 0,25 & Русские & [7] \\
\hline FTO & 16 & rs8050136 & c. $46-27777 C>A$ & Интрон & $96 / 96$ & $\begin{array}{c}1,19 \\
(0,58-2,43) \\
\end{array}$ & 0,05 & Русские & [19] \\
\hline FTO & 16 & rs7202116 & c. $46-22437 A>G$ & Интрон & $440 / 264$ & - & 0,83 & Русские & [7] \\
\hline FTO & 16 & rs9930506 & c.46-13587A>G & Интрон & $440 / 264$ & - & 0,25 & Русские & [7] \\
\hline FTO & 16 & rs1558902 & c. $46-40478 \mathrm{~T}>\mathrm{A}$ & Интрон & $96 / 96$ & - & - & Русские & [19] \\
\hline
\end{tabular}




\begin{tabular}{|c|c|c|c|c|c|c|c|c|c|}
\hline & & & & & & & & Продолжение $n$ & таблицы 1 \\
\hline Ген & $\begin{array}{l}\text { Хромо- } \\
\text { сома }\end{array}$ & RefSNP & Замена & Эффект & $\begin{array}{c}\text { СД2/ } \\
\text { контроль }\end{array}$ & $\begin{array}{c}\text { OR } \\
(95 \% \mathrm{CI})\end{array}$ & $\mathbf{P}$ & $\begin{array}{c}\text { Популя- } \\
\text { ция }\end{array}$ & Ссылка \\
\hline FTO & 16 & rs11642841 & c. $123+1358 C>A$ & Интрон & $96 / 6$ & $\begin{array}{c}1,27 \\
(0,61-2,66)\end{array}$ & 0,04 & Русские & [19] \\
\hline GCLC & 6 & rs17883901 & g.4891C>T & Промотор & $700 / 718$ & $\begin{array}{c}1,69 \\
(1,11-2,58)\end{array}$ & 0,02 & $\begin{array}{c}\text { Русские } \\
\text { (мужчины) }\end{array}$ & {$[48]$} \\
\hline GPX2 & 3 & $\begin{array}{c}\text { rs4602346/ } \\
\text { rs1602698 }\end{array}$ & g.148353411C>G & Межгенный & $1570 / 1609$ & $\begin{array}{c}1,41 \\
(1,02-1,96)\end{array}$ & 0,039 & Русские & {$[49]$} \\
\hline GSTP1 & 11 & rs1695 & c. $313 A>G$ & Ile $>$ Val & $321 / 327$ & $\begin{array}{c}1,39 \\
(1,02-1,90)\end{array}$ & 0,03 & $\begin{array}{c}\text { Русские } \\
\text { (женщины) }\end{array}$ & {$[51]$} \\
\hline GSTT1 & 22 & Делеция & del/del & $\begin{array}{c}54 \text { kb } \\
\text { делеция }\end{array}$ & $321 / 327$ & $\begin{array}{c}2,13 \\
(1,07-4,24)\end{array}$ & 0,02 & $\begin{array}{c}\text { Русские } \\
\text { (мужчины) }\end{array}$ & {$[51]$} \\
\hline HHEX/IDE & 10 & rs7923837 & g.94481917G $>A$ & Межгенный & $204 / 348$ & 1,07 & 0,56 & Якуты & [13] \\
\hline HHEX/IDE & 10 & rs1111875 & g. $94462882 C>G$ & Межгенный & $204 / 348$ & 1,08 & 0,68 & Якуты & [13] \\
\hline HHEX/IDE & 10 & rs1111875 & g. $94462882 C>G$ & Межгенный & $96 / 96$ & - & - & Русские & {$[9]$} \\
\hline HHEX/IDE & 10 & rs1111875 & g. $94462882 C>G$ & Межгенный & $440 / 264$ & $\begin{array}{c}1,03 \\
(0,64-1,65)\end{array}$ & 0,99 & Русские & [57] \\
\hline IGF2BP2 & 3 & rs1470579 & c.239+11861T>G & Интрон & $96 / 96$ & $\begin{array}{c}1,59 \\
(1,01-2,48)\end{array}$ & 0,01 & Русские & [19] \\
\hline IGF2BP2 & 3 & rs11927381 & c. $239+32350 A>G$ & Интрон & $559 / 540$ & $\begin{array}{c}1,33 \\
(1,13-1,56)\end{array}$ & 0,0006 & Русские & [58] \\
\hline IGF2BP2 & 3 & rs4402960 & g.185511687G >T & Интрон & $1470 / 1447$ & $\begin{array}{c}1,05 \\
(0,94-1,19)\end{array}$ & 0,18 & Русские & {$[14]$} \\
\hline IGF2BP2 & 3 & rs11705701 & g.3519C $>\mathrm{T}$ & Промотор & $1470 / 1447$ & $\begin{array}{c}1,21 \\
(1,1-1,36)\end{array}$ & $<0,001$ & Русские & [14] \\
\hline IRS1 & 2 & rs2943634 & g.227068080A $>C$ & Межгенный & $96 / 96$ & $\begin{array}{c}2,30 \\
(1,23-4,32)\end{array}$ & 0,03 & Русские & [19] \\
\hline IRS1 & 2 & rs2943641 & g.227093745T>A & Межгенный & $96 / 96$ & $\begin{array}{c}2,24 \\
(1,24-4,03)\end{array}$ & 0,03 & Русские & [19] \\
\hline KCNJ11 & 11 & rs5219 & g. $5635 A>C$ & $K($ Lys $)>E(G l u)$ & $440 / 264$ & $\begin{array}{c}1,53 \\
(1,03-2,26)\end{array}$ & 0,01 & Русские & [7] \\
\hline KCNJ11 & 11 & rs5219 & g.5635A $>C$ & $\mathrm{~K}(\mathrm{Lys})>(\mathrm{Glu})$ & $204 / 348$ & 1,099 & 0,467 & Якуты & {$[13]$} \\
\hline KCNJ11 & 11 & rs5219 & g.5635A $>C$ & $\mathrm{~K}($ Lys $)>\mathrm{E}(\mathrm{Glu})$ & $376 / 210$ & $\begin{array}{c}1,53 \\
(0,99-2,36)\end{array}$ & 0,029 & Русские & {$[8]$} \\
\hline KCNJ11 & 11 & rs5215 & g.5635A $>C$ & $\mathrm{~K}($ Lys $)>\mathrm{E}(\mathrm{Glu})$ & $204 / 348$ & 1,123 & 0,289 & Якуты & {$[13]$} \\
\hline KCNQ1 & 11 & rs163184 & c. $1795-21928 \mathrm{~T}>\mathrm{C}$ & Интрон & $96 / 96$ & $\begin{array}{c}3,45 \\
(1,20-9,96)\end{array}$ & 0,03 & Русские & [19] \\
\hline KCNQ1 & 11 & rs2237897 & g.397326C >T & Интрон & $204 / 348$ & 1,199 & 0,16 & Якуты & {$[13]$} \\
\hline$L P L$ & 8 & rs285 & c. $1019-1582 C>T$ & Интрон & $204 / 348$ & - & 0,03 & Якуты & {$[13]$} \\
\hline$L P L$ & 8 & rs320 & c. $1322+483 \mathrm{~T}>\mathrm{A}$ & Интрон & $486 / 444$ & $\begin{array}{c}1,24 \\
(1,00-1,53)\end{array}$ & 0,046 & Татары & [44] \\
\hline$L P L$ & 8 & rs320 & c. $1322+483 T>A$ & Интрон & $204 / 348$ & 4,36 & $<0,0005$ & Якуты & [13] \\
\hline$L P L$ & 8 & rs328 & c. $1421 C>G$ & $S($ Ser $)>Y($ Ter $)$ & $204 / 348$ & - & 0,47 & Якуты & [13] \\
\hline
\end{tabular}


Окончание таблицы 1

\begin{tabular}{|c|c|c|c|c|c|c|c|c|c|}
\hline Ген & $\begin{array}{l}\text { Хромо- } \\
\text { сома }\end{array}$ & RefSNP & Замена & Эффект & $\begin{array}{c}\text { СД2/ } \\
\text { контроль }\end{array}$ & $\begin{array}{c}\text { OR } \\
(95 \% \mathrm{Cl})\end{array}$ & $\mathbf{P}$ & $\begin{array}{c}\text { Популя- } \\
\text { ция }\end{array}$ & Ссылка \\
\hline LRP5 & 11 & rs3736228 & c. $3989 C>T$ & $\mathrm{~A}(\mathrm{Ala})>\mathrm{V}(\mathrm{Val})$ & $486 / 444$ & $\begin{array}{c}1,45 \\
(1,04-2,03)\end{array}$ & 0,027 & Татары & [44] \\
\hline$M C 4 R$ & 18 & rs571312 & g.60172536C $>A$ & Межгенный & $96 / 96$ & $\begin{array}{c}8,86 \\
(1,08-72,31)\end{array}$ & 0,03 & Русские & [19] \\
\hline PPARG & 3 & rs1801282 & c. $34 C>G$ & P(Pro) $>A($ Ala $)$ & $96 / 96$ & - & - & русские & {$[34]$} \\
\hline PPARG & 3 & rs1801282 & c. $34 C>G$ & P(Pro) $>A($ Ala $)$ & $391 / 556$ & $\begin{array}{c}1,43 \\
(1,10-1,86)\end{array}$ & $7 \times 10^{-3}$ & русские & {$[22]$} \\
\hline PPARG & 3 & rs1801282 & c. $34 C>G$ & P(Pro) $>A($ Ala $)$ & $294 / 326$ & $\begin{array}{c}0,50 \\
(0,18-1,38)\end{array}$ & 0.26 & Татары & [23] \\
\hline PPARG & 3 & rs1801282 & c. $34 C>G$ & $\mathrm{P}($ Pro $)>A($ Ala $)$ & $204 / 348$ & 1,063 & 0,875 & Якуты & [13] \\
\hline PPARG & 3 & rs3856806 & c. $1347 C>T$ & $\mathrm{H}(\mathrm{His})>\mathrm{H}(\mathrm{His})$ & $204 / 348$ & 1,236 & 0,143 & Якуты & [13] \\
\hline$S L C 2 A 2$ & 3 & rs11924032 & g. $14670 \mathrm{C}>\mathrm{T}$ & Интрон & $96 / 96$ & $\begin{array}{c}1,61 \\
(0,81-3,18)\end{array}$ & 0,04 & Русские & [19] \\
\hline SLC30A8 & 8 & rs13266634 & c. $826 C>A$ & $R(\operatorname{Arg})>W(\operatorname{Trp})$ & $588 / 597$ & $\begin{array}{c}1,35 \\
(1,05-1,68)\end{array}$ & 0,019 & Русские & [8] \\
\hline SLC30A8 & 8 & rs13266634 & c. $826 C>A$ & $R($ Arg $)>W(\operatorname{Trp})$ & $440 / 264$ & $\begin{array}{c}1,36 \\
(0,97-1,94)\end{array}$ & 0,02 & Русские & [7] \\
\hline SCL30A8 & 8 & rs13266634 & $c .826 C>A$ & $\mathrm{R}($ Arg $)>W(\operatorname{Trp})$ & $204 / 348$ & 1,118 & 0,368 & Якуты & [13] \\
\hline TCF7L2 & 10 & rs7903146 & g.746C >T & Интрон & $204 / 348$ & 1,652 & 0,133 & Якуты & [13] \\
\hline TCF7L2 & 10 & rs7903146 & g.746C >T & Интрон & $96 / 96$ & - & - & Русские & {$[34]$} \\
\hline TCF7L2 & 10 & rs7903146 & g.746C $>\mathrm{T}$ & Интрон & $391 / 556$ & $\begin{array}{c}2,04 \\
(1,54-2,71)\end{array}$ & $7 \times 10^{-7}$ & Русские & {$[22]$} \\
\hline TCF7L2 & 10 & rs7903146 & g.746C > T & Интрон & $169 / 286$ & $\begin{array}{c}0,51 \\
(0,34-0,76)\end{array}$ & 0,001 & Татары & [33] \\
\hline TCF7L2 & 10 & rs7903146 & g.746C $>\mathrm{T}$ & Интрон & $440 / 264$ & $\begin{array}{c}2,48 \\
(1,60-3,84)\end{array}$ & 0,0002 & Русские & [24] \\
\hline TCF7L2 & 10 & rs12255372 & g.103894G >T & Интрон & $391 / 556$ & - & - & Русские & [34] \\
\hline TCF7L2 & 10 & rs12255372 & g.103894G >T & Интрон & $440 / 264$ & $\begin{array}{c}1,79 \\
(0,95-3,35)\end{array}$ & 0,18 & Русские & [24] \\
\hline TCF7L2 & 10 & rs12255372 & g.103894G >T & Интрон & $588 / 597$ & $\begin{array}{c}1,47 \\
(1,12-1,81) \\
\end{array}$ & 0,008 & Русские & [8] \\
\hline TMEM18 & 2 & rs2867125 & g.622827T>G & Межгенный & $96 / 96$ & - & - & Русские & {$[19]$} \\
\hline WFS1 & 4 & rs752854 & g. $15385 C>T$ & Интрон & $1112 / 1097$ & $\begin{array}{c}0,86 \\
(0,75-0,96)\end{array}$ & 0,013 & Русские & [21] \\
\hline WFS1 & 4 & rs10010131 & g.26339A >G & Интрон & $1112 / 1097$ & $\begin{array}{c}0,77 \\
(0,68-0,87)\end{array}$ & 0,00024 & Якуты & {$[21]$} \\
\hline WFS1 & 4 & rs734312 & c. $1832 \mathrm{G}>\mathrm{A}$ & $\mathrm{R}($ Arg $)>\mathrm{H}(\mathrm{His})$ & $1112 / 1097$ & $\begin{array}{c}0,73 \\
(0,57-0,94)\end{array}$ & 0,016 & Русские & [21] \\
\hline ZFAND6 & 15 & rs11634397 & g.80139880A >G & Межгенный & - & $\begin{array}{c}1,58 \\
(0,88-2,84)\end{array}$ & 0,03 & Русские & {$[19]$} \\
\hline
\end{tabular}

Примечание: жирным шрифтом выделены статистически значимые различия. В анализ были включены только пациенты с СД2 и здоровый контроль. 
выполненных в популяциях европеоидов и монголоидов, при этом в популяции японцев этот маркер показал себя как наиболее сильный предиктор заболевания с максимальным показателем соотношения шансов $(\mathrm{OR}=1,27)$ [3-4].

Полиморфные варианты гена CDKN2B2A (rs10811661) выявили ассоциацию с развитием СД2 у русских, такая же ассоциация была показана в этнической группе якутов $[7,13]$.

Ген IGF2BP2 кодирует регулятор ростового фактора, связывающего мРНК и непосредственно влияющего на функционирование и выживание бета-клеток островков Лангерганса. В работе D.A. Chistiakov и соавт. (2012) локус rs11705701 гена IGF2BP2 показал ассоциацию с СД2, в работе Вахромеевой К.А. (2015) была показана ассоциация с СД2 другого локуса этого гена $[9,14]$.

Полиморфные локусы rs2283228, rs2237895, rs2237897 гена калиевого потенциал-зависимого канала 1 (KCNQ) были впервые идентифицированы в качестве маркеров риска СД2 в полногеномных поисках, проведенных в монголоидной популяции (японцы), а затем и в европеоидных популяциях [15-17].

В популяции русских была показана ассоциация с СД2 локуса rs163184 гена KCNQ1, в этнической группе якутов маркер rs5215 гена KCNQ1 не подтвердил взаимосвязь с СД2 $[9,13]$.

Ген SLC2A2 кодирует гликопротеин плазматической мембраны островковых бета-клеток GLUT2, который обеспечивает облегченный двунаправленный транспорт глюкозы. Полиморфный локус rs11920090 гена SLC2A2 взаимосвязан с уровнем гликемии натощак, а локус rs11924032 ассоциирован с СД2 у русских $[18,19]$.

Полиморфный локус rs7172432 гена кальций-зависимого домена C2CD4A продемонстрировал ассоциацию с развитием СД2 в европейских (включая русскую) и монголоидных популяциях $[19,20]$.

Известно, что нарушение секреции инсулина зависит от уровня ионов $\mathrm{Zn}^{2+}$ в бета-клетках поджелудочной железы. Ассоциация гена SLC30A8, продукт которого является белком-транспортером ионов цинка 8 типа (ZnT-8), с СД2 установлена в ряде исследований в этнической группе русских $[7,8]$.

В этнических группах русских и якутов выявлена ассоциация гена вольфрамина WFS1 с СД2 [21]. Данный ген кодирует трансмембранный гликопротеин эндоплазматического ретикулума (вольфрамин), регулирующий гомеостаз кальция в клетках поджелудочной железы и нервной системы. Изменения в структуре протеина, кодируемые полиморфными вариантами гена WFS1, могут вызывать нарушение кальциевого обмена, что, в свою очередь, приводит к повреждению секреции инсулина бета-клетками.

Продуктом гена TCF7L2 является бета-катенин, ядерный рецептор канонического активатора Wnt-сигнального пути. Обнаружено, что уменьшение экспрессии TCF7L2 коррелирует с низким содержанием PHK ZnT-8 в бета-клетках. Ассоциация с полиморфными вариантами гена TCF7L2 была установлена у русских, татар [22-24]. Вместе с тем в работах Валеевой Ф.В. и соавт. (2017), Вахромеевой К.А. (2015) значимых различий по распределению частот и генотипов данных локусов гена TCF7L2 в группах пациентов и здоровых лиц у русских и татар выявлено не было $[9,25]$.
Генетические варианты, участвующие в формировании резистентности к инсулину (варианты генов PPARG, IRS1, ADIPOQ и ADIPOR2)

Адипокин секретируется адипоцитами и играет центральную роль в развитии воспалительной реакции, связанной с инсулинорезистентностью, метаболическим синдромом и СД2. Вследствие того, что действие адипонектина на ткани-мишени опосредуется через рецепторы, гены как самого адипонектина, так и рецепторов к нему могут рассматриваться в качестве кандидатных при развитии СД2.

В ходе метаанализа нескольких исследований зарубежных авторов установлена ассоциация аллелей гена адипонектина ADIPOQ (rs16861194, rs266729 и rs2241766) с СД2 [26]. В Российской Федерации полиморфные локусы гена $A D I P O Q$ ассоциированы с СД2 в популяциях якутов (rs2241766) и татар (rs17366743), в популяции русских ассоциации не выявлены [13, 27-30].

Результаты анализа ассоциаций полиморфных локусов генов рецепторов адипонектина в европеоидных популяциях носят противоречивый характер. В популяциях РФ ассоциация была выявлена для маркеров rs11061971 ADIPOR2 и rs16928751 ADIPOR2 у русских $[29,30]$.

Ген PPARG кодирует ядерный рецептор PPAR-gamma (молекулярная мишень для гипогликемизирующих препаратов группы глитазонов), экспрессируется преимущественно в жировой ткани. Это первый ген, ассоциации которого с СД2 воспроизведены в разных популяциях, как европейских, так и азиатских [31, 32]. Нуклеотидная замена c.34C>G приводит к появлению аланина вместо пролина в белке в 12 положении (имеет место у 15\% европеоидов), что обуславливает повышение транскрипционной активности гена.

Бондарь И.А. и соавт. (2013) в своей работе привели результаты анализа ассоциаций rs1801282 гена PPARG (Pro12Ala) с СД2 и показали, что аллельные варианты гена PPARG (rs1801284) ассоциированы с риском СД2 в Новосибирской области [22]. Тогда как в работе Avzaletdinova D.Sh. и соавт. (2016) показано отсутствие ассоциации полиморфного локуса rs 1801282 гена PPARG с СД2 у жителей Башкортостана, также отсутствие ассоциации с СД2 было показано в популяции якутов и русских $[13,33,34]$.

IRS1 - это белок-субстрат тирозиновой протеинкиназы инсулинового рецептора, а также рецептора инсулиноподобного фактора роста 1. Экспрессия гена IRS1 определяется во всех тканях, участвующих в метаболизме глюкозы. Снижение уровня белкового продукта может быть молекулярным маркером инсулинорезистентных состояний и приводить к СД2. Ассоциация IRS1 с СД2 выявлена у русских [19].

\section{Гены воспаления}

Установление в качестве патогенетических звеньев развития СД2 и его осложнений роли хронического воспаления и нарушений ангиогенеза, регуляция которых осуществляется факторами роста и цитокинами, инициировало исследования ассоциаций полиморфизмов генов цитокинов с резистентностью к инсулину и СД2 [35-40].

Коненков В.И. и соавт. (2012) приводят данные анализа ассоциации комбинаций аллельных вариантов 
гена VEGF (vascular endothelial growth factor - cocyдистый эндотелиальный фактор роста) и генов цитокинов (интерлейкин-1, -4, -6, -10 и фактор некроза опухолей а - IL 1B, IL4, IL6, IL 10 и TNFA соответственно) у больных СД2 женщин русской этнической принадлежности [41]. Всего анализировалось 10 однонуклеотидных полиморфизмов (данные по единичным генам не представлены). Авторы делают вывод, что сочетания аллельных вариантов гена VEGF $(A-2578 C$ и $C+936 T)$ и генотипов TNFA (A-238G, A-308G, A-863C), IL 1B (C-31T), IL10 (A-592C, A-1082G), IL6 (G-174C), IL4 (C-590T) могут выступать в качестве генетических маркеров высокого и низкого риска СД2 у женщин европеоидного происхождения. Данные не включены в анализ, поскольку в этой работе не приведено исследований по локусам в отдельности.

В нашем исследовании в этнической группе татар была показана ассоциация с СД2 полиморфных локусов генов хемокинов CCL20 (rs6749704) и CCL5 (rs2107538) (Kochetova O.V. и соавт., 2019) [42].

\section{Гены липидного обмена}

В качестве потенциального кандидатного гена СД2 рассматривается ген липопротеинлипазы $L P L$, вовлеченный в регуляцию липидного обмена и патогенез артериальной гипертензии [43]. Исследования по анализу распределения частот полиморфных вариантов гена $L P L$ у пациентов с СД2 в этнических группах Российской Федерации малочисленны. Ассоциация выявлена в популяциях якутов и татар $[13,44]$.

Ген FABP2 относится к семейству небольших цитоплазматических липидсвязывающих белков. Продукт гена $F A B P 2$, находясь в эпителии кишечника, связывает жирные кислоты. Полиморфные варианты этого гена связаны с более выраженным подъемом уровня триглицеридов после приема пищи, развитием ожирения и СД2. Ассоциация с СД2 показана в этнической группе татар [45].

Ген LRP5 кодирует трансмембранный рецептор липопротеинов низкой плотности, который является также рецептором Wnt сигнального пути. Сигнальный путь Wnt играет ключевую роль в регуляции бета-клеточной функции поджелудочной железы, а также является связующим звеном между адипогенезом и остеогенезом [46, 47]. Ассоциация с СД2 показана в этнической группе татар [44].

\section{Гены биотрансформации ксенобиотиков}

Окислительный стресс служит важной составляющей патогенеза большинства многофакторных заболеваний, не является исключением и СД2. В работах Азаровой Ю.Э. и соавт. $(2017,2018,2019)$ показана ассоциация полиморфных маркеров генов GCLC (rs17883901), GPX2 (rs4602346), GSTP1 (rs 1695) и GSTT1 (делеция) и CYBA с риском развития СД2 у русских [48-51].

Механизм взаимосвязи полиморфных вариантов этих генов с СД2 объясняется увеличением концентрации активных форм кислорода в плазме крови. Усиление окислительного стресса приводит к снижению активности и массы бета-клеток, которые являются весьма уязвимыми ввиду их крайне низких антиоксидантных возможностей [52].

\section{Гены, влияющие на пищевое поведение}

Потенциальными кандидатами развития СД2 являются гены MC4R (рецептора меланокортинстимулирующего гормона 4) и FTO (fat mass and obesity - избыточной массы и ожирения), поскольку одной из частых характеристик пациентов, страдающих СД2, является ожирение.

Продукт гена MC4R влияет на регуляцию пищевого поведения (формирование аппетита), а вместе с этим как на контроль массы тела, так и на резистентность к инсулину. Данные крупного метаанализа свидетельствуют об ассоциации полиморфного локуса rs17782313 гена MC4R с СД2 [53].

Ген FTO кодирует мессенджер, определяемый во многих тканях, но чаще всего в гипоталамусе - центре контроля пищевого поведения. В полногеномных поисках были выявлены ассоциации полиморфных участков rs8050136, rs9939609, rs17817449, rs1421085 гена FTO с СД2 у жителей Западной Европы, белых американцев и афроамериканцев [54].

Вместе с тем в Российской Федерации ассоциация с риском развития СД2 по локусам генов MC4R и FTO получена только в исследованиях Суплотовой Л.А. (2014) и Вахромеевой К.А. (2015) у русских $[9,19]$.

\section{ЗАКЛЮЧЕНИЕ}

В обзоре приведены гены, ассоциированные с СД2, В трех этнических группах РФ. Выявлены как сходные маркеры, характерные для трех популяций, так и различающиеся.

Таким образом, сделан первый шаг в понимании генетической основы СД2 в этнических группах РФ. Анализ данных свидетельствует о том, что полученные на сегодняшний день ассоциации все еще не находят своего применения в клинической практике, поскольку при учете риска необходимо проводить расчет вклада не одного однонуклеотидного локуса, а учитывать аддитивный эффект аллелей различных генов, а также разнообразные факторы внешней среды. Крайне важно проанализировать генетическую эпидемиологию этого заболевания в каждой популяции из-за основных различий в генетическом происхождении и образе жизни различных этнических групп. Раскрытие механизмов патогенеза СД2 поможет понять основы его патофизиологии и способствовать в дальнейшем определению групп высокого риска, проведению профилактических мероприятий и индивидуальной фармакотерапии.

\section{ДОПОЛНИТЕЛЬНАЯ ИНФОРМАЦИЯ}

Источник финансирования. Рукопись подготовлена при финансовой поддержке Российского фонда фундаментальных исследований (№20-013-00261) и Министерства науки и высшего образования Российской Федерации НИР№ АААА-А16-116020350031-4.

Конфликт интересов. Авторы заявляют об отсутствии явных и возможных конфликтов интересов, связанных с публикацией представленной статьи.

Участие каждого автора. Авзалетдинова Д.Ш., Кочетова О.В., Шарипова Л.Ф. - анализ и интерпретация результатов исследования, написание текста статьи. Моругова Т.В. - финальный анализ результатов и редактирование текста рукописи. Все авторы внесли существенный вклад в проведение исследования и подготовку статьи, прочли и одобрили финальную версию перед публикацией. 


\section{СПИСОК ЛИТЕРАТУРЫ | REFERENCES}

1. Morris AP, Voight BF, Teslovich TM, et al. Large-scale association analysis provides insights into the genetic architecture and pathophysiology of type 2 diabetes. Nat. Genet. 2012;44:981-990. doi: https://doi.org/10.1038/ng.2383

2. Scott LI, Mohlke KL, Bonnycastle LL, et al. A genomewide association study of type 2 diabetes in Finns detects multiply susceptibility variants. Science. 2007;316:1341-1345. doi: https://doi.org/10.1126/science.1142382

3. Omori S, Tanaka Y, Takahashi A, et al. Association of CDKAL1, IGF2BP2, CDKN2A/B, HHEX, SLC30A8, and KCNJ11 with susceptibility to type 2 diabetes in a Japanese population. Diabetes. 2008;57:791-795. doi: https://doi.org/10.2337/db07-0979

4. Kong X, Xing X, Hong J, et al. Genetic variants associated with lean and obese type 2 diabetes in a Han Chinese population: a case-control study. Medicine. 2016;95:e3841. doi: https://doi.org/10.1097/MD.0000000000003841

5. Yunusbayev B, Metspalu M, Metspalu E, et al. The genetic legacy of the expansion of Turkic-speaking nomads across Eurasia. PLoS Genet. 2015;11(4):e1005068. doi: https://doi.org/10.1371/journal.pgen.1005068.

6. Федорова С.А., Хуснутдинова Э.К. Генофонд народов республики Саха (Якутия): структура, происхождение, генетические взаимоотношения // Генетика. - 2010. - Т. 46. — №9. C. 1244-1246. [Fedorova SA, Khusnutdinova EK. Gene pool of peoples from the Republic Sakha (Yakutia): structure, origin, genetic relationships. Russian Journal of Genetics. 2010;46(9):1102-1104. (In Russ.)]. doi: https://doi.org/10.1134/S1022795410090231

7. Nikitin AG, Potapov VA, Brovkin AN, et al. Association of FTO, KCNI11, SLC30A8, and CDKN2B Polymorphisms with Type 2 Diabetes Mellitus. Molecular Biology. 2015;49(1):103-111. doi: https://doi.org/10.1134/S0026893315010112

8. Потапов В.А. Поиск генетических маркеров, определяющих предрасположенность к сахарному диабету 2-го типа: Дис. ... канд. мед. наук. — Москва; 2010. [Potapov VA. Poisk geneticheskih markerov, opredeljajushhih predraspolozhennost'k saharnomu diabetu 2-go tipa. [dissertation] Moskva; 2010. (In Russ.)].

9. Вахромеева К.А. Полиморфные генетические маркеры сахарного диабета 2-го типа и их ассоциации с клинико-метаболическими показателями в русской популяции: Дис. ... канд. мед. наук. Тюмень; 2015 [Vahromeeva KA. Polimorfnye geneticheskie markery saharnogo diabeta 2-go tipa i ih associacii skliniko-metabolicheskimi pokazateljami v russkoj populjacii. [dissertation]. Tjumen'; 2015. (In Russ.)].

10. Saxena R, Voight BF, Lyssenko V, et al. Genome-wide association analysis identifies loci for type 2 diabetes and triglyceride levels. Science. 2007;316(5829):1331-1336. doi: https://doi.org/10.1126/science.1142358

11. Zeggini E, Weedon MN, Lindgren CM, et al. Replication of genome-wide association signals in UK samples reveals risk loci for type 2 diabetes. Science. 2007;316(5829):1336-1341. doi: https://doi.org/10.1126/science.1142364

12. Reis $A$, Ye W, Dubois-Laforgue $D$, et al. Association of a variant in exon 31 of the sulfonylurea receptor 1 (SUR1) gene with type 2 diabetes mellitus in French Caucasians. Hum. Genet. 2000;107:138-144. doi: https://doi.org/10.1007/s004390000345

13. Осокина И.В., Платонов Ф.А. Изучение генетической предрасположенности к сахарному диабету 2 типа в якутской популяции // Евразийский Союз Ученых (ЕСУ). - 2018. - Т. 4. №49. - C. 53-57. [Osokina IV, Platonov FA. Izuchenie geneticheskoj predraspolozhennosti k saharnomu diabetu 2 tipa $\vee$ jakutskoj populjacii. Evrazijskij Sojuz Uchenyh (ESU). 2018;4(49):53-57. (In Russ.)].

14. Chistiakov DA, Nikitin AG, Smetanina SA, et al. The rs 11705701 G> A polymorphism of IGF2BP2 is associated with IGF2BP2 mRNA and protein levels in the visceral adipose tissue - a link to type 2 diabetes susceptibility. Rev Diabet Stud. 2012;9(2-3):112-122. doi: https://doi.org/10.1900/RDS.2012.9.112

15. Jonsson A, Isomaa B, Tuomi T, et al. A variant in the KCNQ1 gene predicts future type 2 diabetes and mediates impaired insulin secretion. Diabetes. 2009;58(10):2409-2413. doi: https://doi.org/10.2337/db09-0246

16. Unoki H, Takahashi A, Kawaguchi T, et al. SNPs in KCNQ1 are associated with susceptibility to type 2 diabetes in East Asian and European populations. Nat. Genetics. 2008;40:1098-1102. doi: https://doi.org/10.1038/ng.208
17. Yasuda K, Miyake K, Horikawa Y, et al. Variants in KCNQ1 gene are associated with susceptibility to type 2 diabetes mellitus. Nat. Genetics. 2008;40:1092-1097. doi: https://doi.org/10.1038/ng.207

18. Dupuis J, Langenberg C, Prokopenko I, et al. New genetic loci implicated in fasting glucose homeostasis and their impact on type 2 diabetes risk. Nat. Genet. 2010;42:105-116. doi: https://doi.org/10.1038/ng.520

19. Суплотова Л.А., Вахромеева К.А., Бельчикова Л.Н., Носиков В.В. Поиск ассоциаций полиморфных генетических маркеров с сахарным диабетом 2 типа в русской популяции // Медииинская наука и образование Урала. - 2014. - T. 15. - № 4. - C. 25-28. [Suplotova LA, Vahromeeva KA, Bel'chikova LN, Nosikov VV. Poisk associacij polimorfnyh geneticheskih markerov s saharnym diabetom 2 tipa v russkoj populjacii. Medicinskaja nauka i obrazovanie Urala. 2014;15(4):25-28. (In Russ).]

20. Borglykke A, Grarup N, Sparsø T, et al. Genetic variant SLC2A2 is associated with risk of cardiovascular disease - assessing the individual and cumulative effect of 46 type 2 diabetes related genetic variants. PLoS One. 2012;7(11):e50418. doi: https://doi.org/10.1371/journal.pone.0050418

21. Chistiakov DA, Khodyrev DS, Smetanina SA, et al. A WFS1 haplotype consisting of the minor alleles of rs752854, rs 10010131, and rs 734312 shows a protective role against type 2 diabetes in Russian patients. Rev Diabet Stud. 2010;7(4):285-292.

22. Бондарь И.А., Филипенко М.Л., Шабельникова О.Ю., Соколова Е.А Ассоциация полиморфных маркеров rs7903146 гена TCF7L2 и rs1801282 гена PPARG (Pro12Ala) с сахарным диабетом 2 типа в Новосибирской области // Сахарный диабет. 2013. - T. 16. — №4. - C. 17-22. [Bondar'IA, Filipenko ML, Shabel'nikova OY, Sokolova EA. Rs7903146 variant of TCF7L2 gene and rs18012824 variant of PPARG2 gene (Pro12Ala) are associated with type 2 diabetes mellitus in Novosibirsk population. Diabetes mellitus. 2013;16(4):17-22. (in Russ.)]. doi: https://doi.org/10.14341/DM2013417-22

23. Авзалетдинова Д.Ш., Шарипова Л.Ф., Кочетова О.В., и др. Анализ ассоциаций полиморфного маркера rs7903146 гена TCF7L2 с сахарным диабетом 2 типа в татарской этнической группе, проживающей в Башкортостане // Сахарный диабет. - 2016. T. 19. - №2. - C. 119-124. [Avzaletdinova DS, Sharipova LF, Kochetova OV, et al. The association of TCF7L2 rs7903146 polymorphism with type 2 diabetes mellitus among Tatars of Bashkortostan. Diabetes Mellitus. 2016;19(2):119-124. (In Russ.)]. doi: https://doi.org/10.14341/DM2004138-45

24. Никитин А.Г., Потапов В.А., Бровкин А.Н., и др. Ассоциация полиморфных маркеров гена TCF7L2 с сахарным диабетом типа 2 // Клиническая практика. - 2014. T. 5. - №1. - C. 4-11. [Nikitin A, Potapov V, Brovkin A, et al. Association of the polymorphisms of the TCF7L2 genes with type 2 diabetes. Clinical Practice. 2014;5(1):4-11. (In Russ.)]. doi: https://doi.org/10.17816/clinpract514-11.

25. Валеева Ф.В., Киселева Т.А., Хасанова К.Б., и др. Анализ ассоциаций полиморфных маркеров гена TCF7L2 с сахарным диабетом 2-го типа у жителей Республики Татарстан // Медицинский альманах. — 2017. - T. 6. - №51. - C. 126-129. [Valeeva FV, Kiseleva TA, Hasanova KB, et al. Analiz associacij polimorfnyh markerov gena TCF7L2 s saharnym diabetom 2-go tipa u zhitelej Respubliki Tatarstan. Medicinskij al'manah. 2017;6(51):126-129 (In Russ.)].

26. Chu H, Wang M, Zhong D, et al. ADIPOQ polymorphisms are associated with type 2 diabetes mellitus: a metaanalysis study. Diabetes Metab Res Rev. 2013; 29(7):532-545. doi: https://dx.doi.org/10.1002/dmrr.2424

27. Назарова А.М., Шарафетдинов Х.Х., Плотникова О.А., и др. Изучение полиморфного маркера rs266729 гена ADIPOQ у пациентов с сахарным диабетом 2 типа в российской популяции // Вопросы диетологии. - 2018. - Т. 8. - №3. C. 11-17. [Nazarova AM, Sharafetdinov KK, Plotnikova OA, et al. A study of the rs 266729 polymorphic marker of the ADIPOQ gene in patients with type 2 diabetes mellitus in the Russian population. Vopr. dietol. (Nutrition). 2018;8(3):11-17. (In Russ.)]. doi: https://doi.org/10.20953/2224-5448-2018-3-11-17 
28. Авзалетдинова Д.Ш, Кочетова О.В., Шарипова Л.Ф., и др. Ассоциация аллелей гена адипонектина с сахарным диабетом 2-го типа у жителей Башкортостана // Проблемы эндокринологии. - 2019. T. 65. - №1. - C. 31-38. [Avzaletdinova DS, Kochetova OV, Sharipova LF, et al. Association of adiponectin gene alleles with type 2 diabetes mellitus in residents of Bashkortostan. Problems of Endocrinology. 2019;65(1):31-38. (In Russ.)]. doi: https://doi.org/10.14341/probl9426

29. Potapov VA, Chistiakov DA, Dubinina A, et al. Adiponectin and adiponectin receptor gene variants in relation to type 2 diabetes and insulin resistance-related phenotypes. Rev Diabet Stud. 2008;5(1):28-37. doi: https://doi.org/10.1900/RDS.2008.5.28

30. Ходырев Д.С., Никитин А.Г., Бровкин А.Н., и др. Анализ ассоциации полиморфных маркеров генов ADIPOQ, ADIPOR1 и ADIPOR2 с сахарным диабетом 2 типа // Сахарный диабет. - 2015. T. 18. — №2. [Khodyrev DS, Nikitin AG, Brovkin AN, et al. Association of polymorphisms of the ADIPOQ, ADIPOR1 and ADIPOR2 genes with type 2 diabetes mellitus. Diabetes mellitus. 2015;18(2):5-11. (In Russ.)]. doi: https://doi.org/10.14341/DM201525-11

31. Gouda HN, Sagoo GS, Harding AH, et al. The association between the peroxisome proliferator-activated receptor-gamma2 (PPARG2) Pro12Ala gene variant and type 2 diabetes mellitus: a HuGE review and meta-analysis. Am. J. Epidemiol. 2010; 171(6):645-655. doi: https://doi.org/10.1093/aje/kwp450

32. Altshuler $\mathrm{D}$, Hirschhorn JN, Klannemark M, et al. The common PPARgamma Pro12Ala polymorphism is associated with decreased risk of type 2 diabetes. Nat. Genet. 2000;26(1):76-80. doi: https://doi.org/10.1038/79216

33. Avzaletdinova DS, Sharipova LF, Morugova TV, et al. Association of variable rs 1801282 locus of PPARG2 gene with diabetic nephropathy. Russian Journal of Genetics. 2016;52(8):877-881. doi: https://doi.org/10.7868/S0016675816080038

34. Вахромеева К.А., Суплотова Л.А., Носиков В.В. Полиморфные генетические маркеры сахарного диабета 2 типа в русской популяции // Проблемы эндокринологии. - 2016. - Т. 62. — №5. - C. 10-11. [Vakhromeeva KA, Suplotova LA, Nosikov W. Genetic markers of type 2 diabetes in Russian population. Problems of Endocrinology. 2016;62(5):10-11. (In Russ.)]. doi: https://doi.org/10.14341/probl201662510-11

35. Garcia C, Feve B, Ferré $P$, et al. Diabetes and inflammation: fundamental aspects and clinical implications. Diabetes Metab. 2010;36(5):327-338. doi: https://doi.org/10.1016/j.diabet.2010.07.001

36. Fadini GP, Sartore S, Agostini C, Avogaro A. Significance of endothelial progenitor cells in subjects with diabetes. Diabetes Care. 2007;30(5):1305-1313. doi: https://doi.org/10.2337/dc06-2305

37. Шварц В. Воспаление жировой ткани. Часть 2. Патогенетическая роль при сахарном диабете 2 типа // Проблемы эндокринологии. - 2009. - Т. 55. - №5. - С. 43-48. [Shvarts V. Inflammation of adipose tissue. Part 2. Pathogenetic role in type 2 diabetes mellitus. Problems of Endocrinology. 2009;55(5):43-48. (In Russ.)]. doi: https://doi.org/10.14341/probl200955543-48

38. Willer CJ, Bonnycastle LL, Conneely KN, et al. Screening of 134 single nucleotide polymorphisms (SNPs) previously associated with type 2 diabetes replicates association with 12 SNPs in nine genes. Diabetes. 2007;56(1):256-264. doi: https://doi.org/10.2337/db06-0461

39. Ho KT, Shiau MY, Chang YH, et al. Association of interleukin-4 promoter polymorphisms in Taiwanese patients with type 2 diabetes mellitus. Metabolism. 2010;59(12):1717-1722. doi: https://doi.org/10.1016/.metabol.2010.04.010

40. Susa S, Daimon M, Sakabe J, et al. A functional polymorphism of the TNF-alpha gene that is associated with type $2 \mathrm{DM}$. Biochem. Biophys. Res. Commun. 2008;369(3):943-947. doi: https://doi.org/10.1016/j.bbrc.2008.02.121

41. Коненков В.И., Шевченко А.В., Прокофьев В.Ф., и др. Ассоциации вариантов гена фактора роста сосудистого эндотелия (VEGF) и генов цитокинов (IL-1B, IL-4, IL-6, IL-10, TNFA) с сахарным диабетом 2 типа у женщин // Сахарный диабет. - 2012. №3. - C. 4-10. [Konenkov VI, Shevchenko AV, Prokof'ev VF, et al. Associations of vascular endothelial growth factor (VEGF) gene and cytokine (IL-1B, IL-4, IL-6, IL-10, TNFA) genes combinations with type 2 diabetes mellitus in women. Diabetes mellitus. 2012;3:4-10. (In Russ.)]. doi: https://doi.org/10.14341/2072-0351-6079

42. Kochetova OV, Avzaletdinova DS, Morugova TV, Mustafina OE, Chemokine Gene Polymorphisms Association with Increased Risk of Type 2 Diabetes Mellitus in Tatar Ethnic Group, Russia. Mol Biol Rep. 2019;46:887-896. doi: https://doi.org/10.1007/s11033-018-4544-6
43. Николаев И.В., Мулюкова Р.В., Каюмова Л.Р., и др. Анализ взаимодействия аллелей генов липидного обмена при дислипидемии // Вавиловский журнал генетики и селекиии. 2014. — T. 18. — №4-2. - C. 856-866. [Nikolaev IV, Mulyukova RV, Kayumova LR, et al. Analysis of the interaction of lipid metabolism alleles in dyslipudemia. Vavilovskii zhurnal genetiki i selectii. 2014;18(4-2):856-866. (In Russ.)].

44. Kochetova OV, Avzaletdinova DS, Sharipova LF, et al. An analysis of the associations of polymorphic variants of the LEPR (rs1137100), LRP5 (rs3736228), and LPL (rs320) genes with the risk of developing type 2 diabetes mellitus. Russian Journal of Genetics. 2019;55(4):495-503. doi: https://doi.org/10.1134/S1022795419040057

45. Валеева Ф.В., Хасанова К.Б., Валеева Е.В., и др. Ассоциация полиморфизма rs 1799883 гена FABP2 с различными нарушениями углеводного обмена у жителей Республики Татарстан // Медицинский альманах. - 2018. - Т. 6. - №57. - С. 116-120. [Valeeva FV, Hasanova KB, Valeeva EV, et al. Associacija polimorfizma rs1799883 gena FABP2 s razlichnymi narushenijami uglevodnogo obmena u zhitelej Respubliki Tatarstan. Medicinskij al'manah. 2018;6(57):116-120. (In Russ.)].

46. Foer $\mathrm{D}, \mathrm{Zhu} \mathrm{M}$, Cardone RL, et al. Impact of gain-of-function mutations in the low-density lipoprotein receptor-related protein 5 (LRP5) on glucose and lipid homeostasis. Osteoporosis Intern. 2017;28(6):2011-2017.

47. Guo YF, Xiong DH, Shen $\mathrm{H}$, et al. Polymorphisms of the lowdensity lipoprotein receptor-related protein 5 (LRP5) gene are associated with obesity phenotypes in a large family-based association study. Journal of medical genetics. 2006;43(10):798-803. doi: https://doi.org/10.1136/jmg.2006.041715

48. Азарова Ю.Э., Клесова Е.Ю., Конопля А.И. Роль полиморфизмов генов глутаматцистеинлигазы в развитии сахарного диабета 2 типа у жителей Курской области // Научный результат. Медицина и фармачия. - 2018. - Т. 4. №1. - C. 39-52. [Azarova YE, Klyosova EY, Konoplya Al. The role of polymorphisms of glutamate-cysteine ligase in type 2 diabetes mellitus susceptibility in Kursk population. Research Result. Medicine and Pharmacy. 2018;4(1):39-52. (In Russ.)]. doi: https://doi.org/10.18413/2313-8955-2018-4-1-39-52

49. Азарова Ю.Э., Клёсова Е.Ю., Бушуева О.Ю., и др. Полиморфный вариант гена GPX2 (rs4902346) и предрасположенность к сахарному диабету 2-го типа // Медицинская генетика. 2020. - T. 19. — №2. - C. 17-27. [Azarova IE, Klyosova EY, Samgina TA, et al. Polymorphic variant in gpx2 gene (rs4902346) and predisposition to type 2 diabetes mellitus. Medical Genetics. 2020;19(2):17-27. (In Russ.)]. doi: https://doi.org/10.25557/2073-7998.2020.02.17-27

50. Азарова Ю.Э., Клёсова Е.Ю., Самгина Т.А., и др. Роль полиморфных вариантов гена СҮВА в патогенезе сахарного диабета 2 типа // Медииинская генетика. - 2019. T. 18. - №8. - C. 37-48. [Azarova IE, Klyosova EY, Samgina $T A$, et al. Role of cyba gene polymorphisms in pathogenesis of type 2 diabetes mellitus. Medical Genetics. 2019;18(8):37-48. (In Russ.)]. doi: https://doi.org/10.25557/2073-7998.2019.08.37-48

51. Азарова Ю.Э., Конопля А.И., Полоников А.В. Полиморфизм генов глутатион S-трансфераз и предрасположенность к сахарному диабету 2 типа у жителей Центрального Черноземья // Медицинская генетика. — 2017. - Т. 16. — №4. - С. 29-34. [Azarova IE, Konoplya Al, Polonikov AV. Genetic variation in genes for glutathione S-Transferases and susceptibility to type 2 diabetes mellitus in Central Chernozem region of Russia. Medical Genetics. 2017;16(4):29-34. (In Russ.)]

52. Аметов А.С., Соловьева ОЛ. Окислительный стресс при сахарном диабете 2-го типа и пути его коррекции // Проблемы эндокринологии. - 2011. - Т. 57. - №6. - C. 52-56. [Ametov AS, Solov'eva OL. Oxidative stress in type 2 diabetes mellitus and methods for its correction. Problems of Endocrinology. 2011; 57(6):52-56. (In Russ.)].

53. Xi B, Takeuchi F, Chandak GR, et al. Common polymorphism near the MC4R gene is associated with type 2 diabetes: data from a metaanalysis of 123,373 individuals. Diabetologia. 2012;55:2660-2666. doi: https://doi.org/10.1007/s00125-012-2655-5

54. Bressler J, Kao WHL, Pankow JS, Boerwinkle E. Risk of Type 2 Diabetes and Obesity Is Differentially Associated with Variation in FTO in Whites and African-Americans in the ARIC Study. FTO, Diabetes, and Obesity. 2010;5(5):e10521. doi: https://doi.org/10.1371/journal.pone.0010521 
55. Осаковский В.Л., Гольдфарб Л.Г., Яковлева М.Н., и др. Изучение вариантов генов, кодирующих субъединицы SUR1 (ген ABCC8) и KIR6 (ген KCNJ11) KATФ-канала бета-клеток панкреатической железы, ассоциирующихся с диабетом 2 типа у представителей якутской популяции // Якутский медицинский журнал. - 2008. №4(24). - C. 76-77. [Osakovskij VL, Gol'dfarb LG, Jakovleva MN, et al. Izuchenie variantov genov, kodirujushhih sub'edinicy SUR1 (gen ABCC8) i KIR6 (gen KCNJ11) KATF kanala beta kletok pankreaticheskoj zhelezy, associirujushhih s diabetom 2 tipa u predstavitelej jakutskoj populjacii. Jakutskij medicinskij zhurnal. 2008;4(24):76-77. (In Russ.)].

56. Алексеева Л.Л., Гольдфарб Л.Г., Самбуугин Х., и др. Анализ ассоциации полиморфного варианта гена адипонектина (ADIPOQ) с риском развития диабетической ретинопатии у якуток, больных сахарным диабетом типа 2 // Вестник СевероВосточного федерального университета им. М.К. Аммосова. 2011. - T. 8. - №3. - C. 27-31. [Alexeyeva LL, Goldfarb LG, Sambuugin $\mathrm{H}$, et al. Analysis of adiponectin gene (ADIPOQ) polymorphic variant association with risk of diabetic retinopathy in Yakut female with sugar diabetes of type 2. Vestnik SeveroVostochnogo federal'nogo universiteta im. M.K. Ammosova. 2011;8(3):27-31. (In Russ.)].

57. Khodyrev DS, Nikitin AG, Brovkin AN, et al. The analysis of association between type 2 diabetes and polymorphic markers in the CDKAL1 gene and in the HHEX/IDE locus. Russian Journal of Genetics. 2016;52(11):1192-1199. doi: https://doi.org/10.7868/S0016675816110060

58. Азарова Ю.Э., Клёсова Е.Ю., Сакали С.Ю., Ковалев А.П. Вклад полиморфизма rs1 1927381 гена IGF2BP2 в патогенез сахарного диабета 2 типа // Научные результаты биомедицинских исследований. — 2020. - T. 6. - №1. - C. 9-19. [Azarova IE, Klyosova EY, Sakali SY, Kovalev AP. Contribution of rs1 1927381 polymorphism of the IGF2BP2 gene to the pathogenesis of type 2 diabetes. Research Results in Biomedicine. 2020; 6(1):9-19. (In Russ.)]. doi: https://doi.org/10.18413/2658-6533-2020-6-1-0-2

\section{ИНФОРМАЦИЯ ОБ АВТОРАХ [AUTHORS INFO]}

*Авзалетдинова Диана Шамилевна, к.м.н., доцент [Diana S. Avzaletdinova, MD, PhD, assistant professor]; адрес: Россия, 450008, Уфа, ул. Ленина, д. 3 [address: 3, Lenina street, 450008 Ufa, Russia]; ORCID: https://orcid.org/0000-0002-1590-6433; eLibrary SPIN: 5540-6951; e-mail: hyppocrat@mail.ru

Моругова Татьяна Вячеславовна, д.м.н., проф. [Tatiana V. Morugova, MD, PhD, Professor]; ORCID: https://orcid.org/0000-0001-7405-486X; eLibrary SPIN: 2976-9605; e-mail: tmorugova@yandex.ru

Шарипова Ляйсан Фаритовна [Liaisan F. Sharipova]; ORCID: https://orcid.org/0000-0003-4866-0983; eLibrary SPIN: 6997-7627; e-mail: nauruzovaleisan@mail.ru

Кочетова Ольга Владимировна, к.б.н. [Olga V. Kochetova, PhD in Biology]; ORCID: https://orcid.org/0000-0003-2071-0969; eLibrary SPIN: 3461-3952; e-mail: olga_mk78@mail.ru

\section{ЦИТИРОВАТЬ:}

Авзалетдинова Д.Ш., Моругова Т.В., Шарипова Л.Ф., Кочетова О.В. Ассоциация полиморфных локусов предрасположенности к сахарному диабету 2 типа в различных этнических группах Российской Федерации // Сахарный диабет. 2021. — T. 24. — №3. — С. 262-272. doi: https://doi.org/10.14341/DM12531

\section{TO CITE THIS ARTICLE:}

Avzaletdinova DS, Morugova TV, Sharipova LF, Kochetova OV. Association of polymorphic loci of susceptibility to diabetes mellitus type 2 in various ethnic groups of the Russian Federation. Diabetes Mellitus. 2021;24(3):262-272. doi: https://doi.org/10.14341/DM12531 